\title{
Does Obstructive Sleep Apnea (OSA) Increase the Risk of Post-Operative Respiratory Complications after Bariatric Surgery?
}

\author{
Ayman A. Elrashidy1, Mohamed Elsherif', Wahiba Elhag'2, Reda Sobhi Abdel-Rahman', \\ S. Abdelaziem ${ }^{3,4}$ \\ ${ }^{1}$ Anesthesia Department, Faculty of Medicine, Tanta University, Tanta, Egypt \\ ${ }^{2}$ Bariatric and Metabolic Surgery Department, Hamad Medical Corporation, Doha, Qatar \\ ${ }^{3}$ Surgery Department, Faculty of Medicine, Tanta University, Tanta, Egypt \\ ${ }^{4}$ Surgery Department, Hamad Medical Corporation, Doha, Qatar \\ Email: elrashidy66@hotmail.com
}

How to cite this paper: Elrashidy, A.A., Elsherif, M., Elhag, W., Abdel-Rahman, R.S. and Abdelaziem, S. (2018) Does Obstructive Sleep Apnea (OSA) Increase the Risk of Post-Operative Respiratory Complications after Bariatric Surgery? Open Journal of Anesthesiology, 8, 255-266.

https://doi.org/10.4236/ojanes.2018.810026

Received: September 5, 2018

Accepted: October 26, 2018

Published: October 29, 2018

Copyright $(9) 2018$ by authors and Scientific Research Publishing Inc. This work is licensed under the Creative Commons Attribution International License (CC BY 4.0).

http://creativecommons.org/licenses/by/4.0/

\begin{abstract}
Background: OSA affects up to quarter of general population. It is associated with morbid obesity with a higher morbidity and mortality rates. STOP Bang questionnaire is a validated method for OSA screening. OSA patients are at high risk of developing airway obstruction, cardiac events, congestive heart failure, stroke and desaturation post operatively. The aim of this study is to evaluate adverse respiratory events in patients undergoing bariatric surgery in relation to risk of OSA using Stop Bang questionnaire. Methods: This prospective double cohort study was conducted in Tanta University Hospital from Marchto August 2017. During the preoperative assessment, STOP-BANG questionnaire was performed. After extubation, patients were transferred to PACU unit. Respiratory complications were assessed thereafter. Based on STOP-BANG score, patients were divided into two groups, high risk of OSA with STOP-BANG $>3$ (Group I) and low risk of OSA with STOP-BANG $<3$ (Group II). Results: 104 patients were included in this study. Group I had more comorbidities in the form of CAD ( $15 \%$ versus $2 \%, \mathrm{P}<0.001)$, dyslipidemia $(28 \%$ versus $11 \%, \mathrm{P}<0.001)$ and diabetes on insulin treatment $(38 \%$ versus $6 \%, \mathrm{P}>0.001)$. Higher number of respiratory complications was noted in high-risk group (31 patients, 59\%) compared to (24 patients, 46\%) in group II yet, it was not significant. Conclusion: Obese patients with STOP-BANG score $>3$ undergoing bariatric surgery are associated with hypertension, dyslipidemia, CAD, and renal insufficiency. High-risk OSA obese patients are at higher risk of developing respiratory compilations like inability to breathe deeply and hypoxia in postoperatively.
\end{abstract}




\section{Keywords}

Obstructive Sleep Apnea (OSA), Respiratory Complications, Morbid Obesity, Bariatric Surgery, STOP-BANG Score

\section{Introduction}

Obstructive sleep apnea can affect up to quarter of general population, it is a common sleep disorder affecting all age groups [1] [2].

Patients with morbid obesity are having a higher prevalence of OSA and further more increase in co-existing medical diseases [3] [4] [5].

It was shown that mortality rates are higher among patients with OSA [6] [7].

Furthermore, post-operative period carries increased risk for adverse respiratory events in such patients [8] [9].

Diagnosis of OSA based mainly upon overnight polysymnography which is still considered the most accurate method for diagnosis of OSA [10].

However, doing polysymnography to all patients as a pre-operative assessment remains a challenge due to its high cost and unavailability in large number of hospitals. For such, a large number of patients with OSA were not diagnosed pre-operatively [10] [11] and screening for these category of patients is of utmost importance [11] [12] [13].

Berlin questionnaire, STOP questionnaire and the American society of anesthesiologists check test were all recognized effective methods for screening OSA pre operatively [1] [9] [14] [15].

Mahesh et al. in year 2017 had proposed STOP Bang questionnaire as a validated method for OSA screening [16].

STOP Bang consists of 8 questions assessing snoring, tiredness during day time, observed apnea, high blood pressure, body mass index, age, neck circumference and gender [12].

Score based on (Yes/No) answers are represented by $(1 / 0)$ score and a total score of more than or equal to 3 is associated with more than $93 \%$ of OSA diagnosis [12].

Bariatric surgery patients represented the commonest group of patients where OSA could be diagnosed. Up to three quarters of such group are suffering OSA together with other obesity related co-morbidities [17] [18]. In such group of patients, numerous risk factors were identified and OSA represented an independent risk factor for peri-operative complications [19].

Patients suffering OSA are at high risk of developing air way obstruction, cardiac events, congestive heart failure, stroke and desaturation post operatively [19] [20].

During general anesthesia, usage of anesthetic medications and sedation and neuromuscular blocking agents may result in prolonged period of apnea during recovery [13]. 
Several studies addressed peri-operative respiratory complications in OSA patients. However, scanty number of published articles could be found addressing the occurrence of adverse respiratory effects in morbidly obese patients associated with OSA undergoing bariatric surgery procedures. Moreover, this study will highlight the importance of diagnosing OSA, using STOP BANG questionnaire, prior to bariatric surgery as a step to avoid expected respiratory complications in post-operative period.

\section{Objectives}

The objective of this study is to evaluate adverse respiratory events in patients undergoing bariatric surgery in relation to risk of obstructive sleep apnea using Stop Bang questionnaire.

\subsection{Methods}

Ethical approval for the current study was obtained from Tanta University Hospital committee. Patients were consented for participation in the study.

The study is a prospective double cohort, conducted in post anesthesia care unit (PACU) in Tanta University Hospital over a period of six months "from first of March to the end of August 2017).

A written informed consent was obtained from all patients.

Patients included in this study were all adult residence in Delta region in Egypt, they all carry the characteristics of middle eastern people with almost similar socioeconomic standards living modern sedentary life.

Inclusion criteria: 1) Adult patients of both genders, 2) Age between 18 - 70 years old, 3) All having Egyptian nationality, 4) BMI of more than $30 \mathrm{kgm} / \mathrm{m}^{2}, 5$ ) Scheduled for bariatric surgery procedure.

All post bariatric surgery patients were transferred to PACU after general anesthesia and were included in this study.

Exclusion criteria were: 1) patient refusal, 2) Extreme of age "less than 18 and more than 70", 3) Known neuromuscular disease, 4) Patients with end organ renal or hepatic failure, 5) Alcohol abuse or addiction, 6) Chronic obstructive pulmonary disease.

During the preoperative assessment done one day before surgery, full medical, surgical history and STOP-BANG questionnaire were obtained (Table 1).

Anesthesia was conducted based on standards of anesthesia department of Tanta University Hospital and anesthesiologists were blinded for our patients.

All patients fasted 8 hours before surgery, neuromuscular blocking drug "Cisatracurium" was used for tracheal intubation at initial dose of $0.15 \mathrm{mg} / \mathrm{kg}$ and maintenance of $0.03 \mathrm{mg} / \mathrm{kg}$ to all of them.

Monitoring of the neuromuscular blockade through TOF intraoperatively and all patients received reversal of neuromuscular blockade with Neostigmine.

Extubation took place in the operating room, patients were transferred to PACU thereafter. 
Table 1. STOP-BANG Questionnaire. High risk of OSA (yes > 3) Questions. Low risk of OSA (yes < 3) questions.

\begin{tabular}{lcc}
\hline SNORING: do you snore loudly (loud enough to be heard through closed doors)? & YES NO \\
TIRED: do you often feel tired, fatigued, or sleepy during daytime? & YES NO \\
OBSERVED: has anyone observed you stop breathing during your sleep? & YES NO \\
BLOOD PRESSURE: do you have or are you being treated for high blood pressure? & YES NO \\
BMI more than $35 \mathrm{kgm} / \mathrm{m}^{2}$ ? & YES NO \\
AGE: age over 50 years old? & YES NO \\
NECK circumference: neck circumference $>40 \mathrm{~cm} ?$ & YES NO \\
GENDER: male? & YES NO \\
\hline
\end{tabular}

For patient safety, face mask with 100\% Oxygen was used for our patients after tracheal extubation and continued till patient admission to PACU.

Patient data sheet was completed and it included age, gender, weight, height, BMI, sedation received perioperatively, type of bariatric procedure, duration of surgery, respiratory adverse events in PACU, VAS score for pain, nausea and vomiting post operatively, length of stay in PACU in minutes, hospital length of stay in days.

Based on STOP-BANG score, patients were divided into two groups, high risk of obstructive sleep apnea (OSA) with STOP-BANG > 3 (Group I) and low risk of obstructive sleep apnea (OSA) with STOP-BANG $<3$ (Group II).

High risk of OSA patients were identified and compared with age and gender matched low risk OSA group on one to one basis.

Variables subjected to statistical analysis obtained from patient's medical records included:

1) Demographic data "age, gender, BMI"

2) American Society of Anesthesiologist and Physical Status, ASAPS (I, II/III, IV)

3) Co morbidities "ischemic heart disease, congestive heart failure, renal impairment, hypertension, dyslipidemia, diabetes with insulin treatment

4) Type of bariatric procedure "Laparoscopic sleeve gastrectomy (LSG), Gastric bypass (RYGBP), Single anastomosis duodenoileal bypass (SADI), Mini gastric bypass

5) Benzodiazepine pre medication

6) Duration of anesthesia

7) Respiratory events in PACU

8) Length of stay in PACU

9) Length of hospital stay

Patient was considered to have respiratory complication if he developed any of the following manifestations: Upper airway obstruction requiring an intervention, hypoxia while the patient was on 3 Liter oxygen mask, respiratory distress or impending ventilatory failure, inability to breathe deeply upon request, 
difficulty in breathing, swallowing or speaking (symptoms of respiratory muscle weakness), reintubation in PACU, signs of pulmonary aspiration after extubation.

\subsection{Statistical Analysis}

Data were collected and summarized using analysis of descriptive variables. Comparison between different groups was carried out using Mann-Whitney U test, Qi square test and Fischer test were used for comparison between sub groups.

Significant results were considered when $\mathrm{P}$ is $<0.05$.

SPSS for windows software, version 19.00 was used for statistical analysis of our data.

\section{Results}

Current study included a total number of 104 patients who were admitted to PACU in Tanta University Hospital during the period between March and August 2017. Demographic data and ASA PS characteristics are shown in Table 2 in group I and II.

Median age was found to be 58 years in both groups with male to female ratio of almost 1:4.

Males were $13(25 \%)$ patients in group I and 12 male patients in group II (23\%).

$67 \%$ of our patients were having ASA I \& II, while $33 \%$ were ASA III \& IV in group I, while $78 \%$ were ASA I \& II and $22 \%$ were having ASA III \& IV in group II.

Table 2. Demographic, clinical data, BMI and ASA PS in both groups.

\begin{tabular}{cccc}
\hline & $\begin{array}{c}\text { Group I, High Risk for } \\
\text { OSA (No 52) }\end{array}$ & $\begin{array}{c}\text { Group II (Low Risk for } \\
\text { OSA (No 52) }\end{array}$ & Significance \\
\hline Age in years & $58(43-68)$ & $58(42-70)$ & $0.868^{\mathrm{a}}$ \\
Gender & $13(25 \%)$ & $12(23 \%)$ & $1^{\mathrm{b}}$ \\
Male & $39(75 \%)$ & $40(77 \%)$ & \\
Female & $139(121-163)$ & $142(122-166)$ & $0.671^{\mathrm{a}}$ \\
Mean weight in Kgms & $84(79-88)$ & $86(78-89)$ & $0.291^{\mathrm{a}}$ \\
Mean Pulse & $93(90-109)$ & $84(80-103)$ & $0.641^{\mathrm{a}}$ \\
Mean Blood pressure & $22(21-24)$ & $21(19-24)$ & $0.439^{\mathrm{a}}$ \\
Mean Respiratory rate & $94(93-98)$ & $96(94-99)$ & $0.348^{\mathrm{a}}$ \\
Mean SPO & $38(31-44)$ & $41(39-52)$ & $0.793^{\mathrm{a}}$ \\
Mean BMI (kgm/m $\left./ \mathrm{m}^{2}\right)$ & $35(67 \%)$ & & $0.171^{\mathrm{b}}$ \\
ASA PS & $17(33 \%)$ & $11(22 \%)$ & \\
I/II & III/IV & &
\end{tabular}

ASA PS: American Society of Anesthesia Physical Status. SPO2: Oxygen Saturation. BMI: Body mass index. a: Mann-Whitney U test; b: Pearson's chi-squared test; c: Fisher's exact test. 
BMI showed no statistical difference between both groups while more frequent comorbidities were associated with group I patients.

Table 3 and Figure 1 show comorbidities in both groups among our study sample including diabetes on insulin treatment, coronary artery disease (CAD), congestive heart failure $(\mathrm{CHF})$, hypertension, dyslipidemia and renal impairment.

Patients of group I had more comorbidities in the form of CAD (15\% versus $2 \%, \mathrm{P}<0.001)$, dyslipidemia $(28 \%$ versus $11 \%, \mathrm{P}<0.001)$ and diabetes on insulin treatment (38\% versus6\%, $\mathrm{P}>0.001)$.

Table 4 showed types of bariatric procedures in both groups and clearly showed no statistical significant difference between both groups.

Table 5 showed duration of anesthesia in both groups. Despite longer anesthesia duration in low risk group (110 minutes) yet, no statistical significant difference between both groups was noted.

Length of hospital stay as well as stay in PACU after surgery showed no statistical significant difference in both groups.

Respiratory adverse events were showed in Table 6 and Figure 2. Although higher number of respiratory complications were noted in high risk group (31 patients, 59\%), no significant difference was found when compared to group II (24 patients, $46 \%)$.

Table 3. Comorbidities in both groups.

\begin{tabular}{cccc}
\hline & $\begin{array}{c}\text { Group I, High Risk for } \\
\text { OSA (No 52) }\end{array}$ & $\begin{array}{c}\text { Group II (Low Risk for } \\
\text { OSA (No 52) }\end{array}$ & Significance \\
\hline DM on insulin & $20(38.4 \%)$ & $3(5.7 \%)$ & $0.004^{\mathrm{c}}$ \\
CAD & $8(15.3 \%)$ & $1(2 \%)$ & $0.004^{\mathrm{c}}$ \\
CHF & $2(3.8 \%)$ & $1(2 \%)$ & $0.525^{\mathrm{c}}$ \\
Hypertension & $35(67 \%)$ & $31(59.6 \%)$ & $0.552^{\mathrm{c}}$ \\
Dyslipidemia & $28(53.8 \%)$ & $11(21 \%)$ & $<0.002^{\mathrm{b}}$ \\
Renal impairment & $2(3.8 \%)$ & $4(7.6 \%)$ & $0.340^{\mathrm{c}}$ \\
\hline
\end{tabular}

DM: diabetes millets; CAD: coronary artery disease; CHF: congestive heart failure. a: Mann-Whitney U test; b: Pearson's chi-squared test; c: Fisher's exact test.

Table 4. Types of bariatric procedures.

\begin{tabular}{cccc}
\hline & $\begin{array}{c}\text { Group I, High Risk for } \\
\text { OSA (No 52) }\end{array}$ & $\begin{array}{c}\text { Group II (Low Risk for } \\
\text { OSA (No 52) }\end{array}$ & Significance \\
\hline LSG & $41(79 \%)$ & $37(71 \%)$ & $0.493^{\mathrm{b}}$ \\
RYGB & $8(15 \%)$ & $11(21 \%)$ & $0.524^{\mathrm{b}}$ \\
SADI & $2(4 \%)$ & $3(6 \%)$ & $0.461^{\mathrm{b}}$ \\
Mini gastric Bypass & $1(2 \%)$ & $1(2 \%)$ & $0.311^{\mathrm{b}}$ \\
\hline
\end{tabular}

LSG: Laparoscopic sleeve gastrectomy; RYGB: Roux-en-Y Gastric Bypass; SADI: Single anastomosis duodeno-ileal bypass with sleeve gastrectomy. a: Mann-Whitney U test; b: Pearson's chi-squared test; c: Fisher's exact test. 


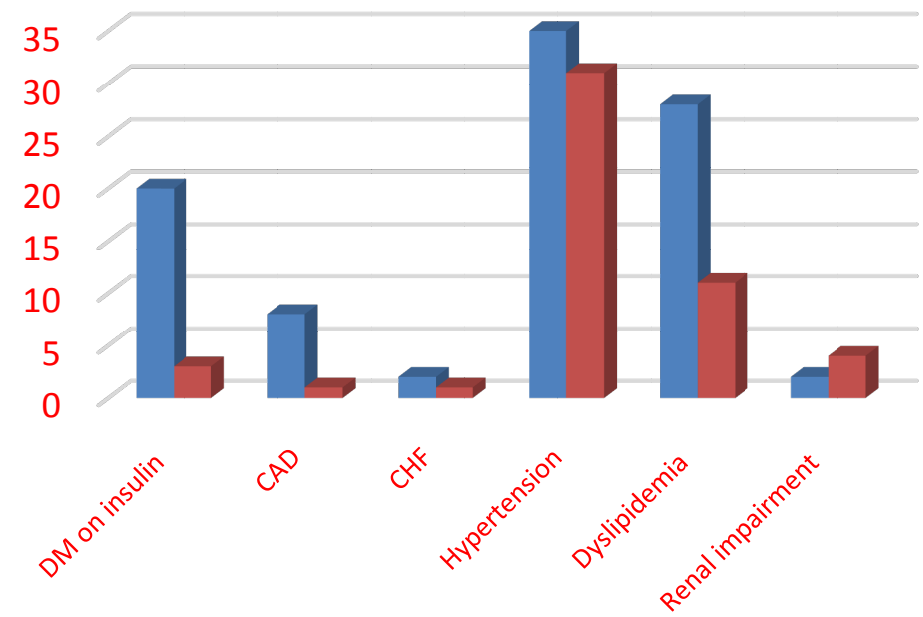

- Group I Group II

Figure 1. Comorbidities in both groups.

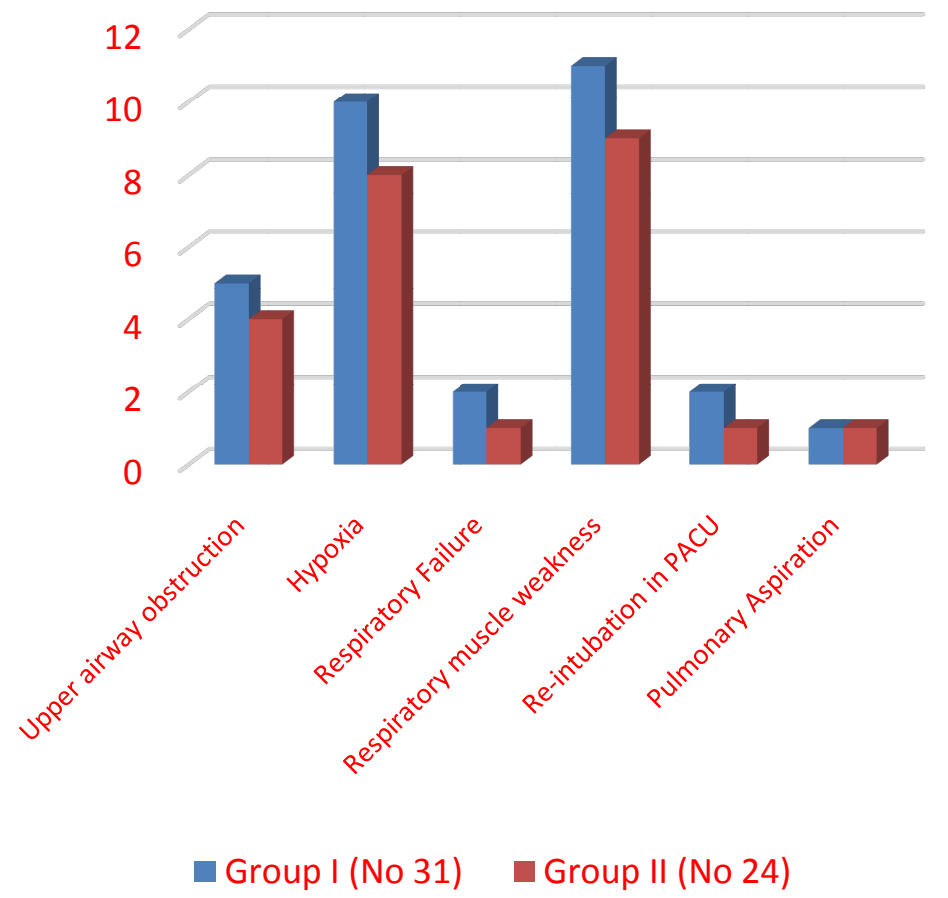

Figure 2. Respiratory complications in both groups.

Table 5. Duration of anesthesia, length of stay in PACU and length of hospital stay.

\begin{tabular}{cccc}
\hline & $\begin{array}{c}\text { Group I, High Risk } \\
\text { for OSA (No 52) }\end{array}$ & $\begin{array}{c}\text { Group II (Low Risk } \\
\text { for (No 52) }\end{array}$ & Significance \\
\hline Duration of anesthesia (minutes) & $105(80-185)$ & $110(80-190)$ & $0.179^{c}$ \\
Length of stay in PACU (minutes) & $125(85-165)$ & $105(80-130)$ & $0.061^{c}$ \\
Length of hospital stay (days) & $5(3-8)$ & $4(2-6)$ & $0.072^{c}$ \\
\hline
\end{tabular}

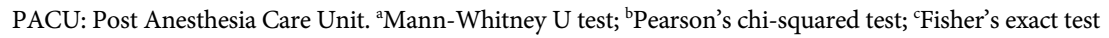


Table 6. Respiratory complications in both groups.

\begin{tabular}{cccc}
\hline & $\begin{array}{c}\text { Group I, High Risk } \\
\text { for OSA (No 31) }\end{array}$ & $\begin{array}{c}\text { Group II (Low Risk } \\
\text { for OSA (No 24) }\end{array}$ & Significance \\
\hline Upper airway obstruction & 5 & 4 & 0.423 \\
Hypoxia & 10 & 8 & 0.395 \\
Respiratory Failure & 2 & 1 & 0.335 \\
Respiratory muscle weakness & 11 & 9 & 0.556 \\
Re-intubation in PACU & 2 & 1 & 0.350 \\
Pulmonary Aspiration & 1 & 1 & 0.455 \\
\hline
\end{tabular}

a: Mann-Whitney U test; b: Pearson's chi-squared test; c: Fisher's exact test.

\section{Discussion}

Several studies had proved the association between OSA and obesity related comorbidities [21] [22].

Our current study showed that patients with STOP-BANG $>3$ (High risk for OSA) had increased incidence of CAD, Dyslipidemia and diabetes mellitus on insulin therapy [21] [22].

Our obese patients showed higher incidence of hypertension and renal impairment regardless the severity of OSA [23].

Associating between CHF and OSA that was reported in different studies couldn't be proved in the current study [21] [22]. This could be partially explained by relatively young age of our group sample.

The majority of obese patient suffering from OSA remain undiagnosed, this may lead to serious respiratory complications in post-operative period [10].

Polysymnography (PSG) remains the gold standard for diagnosis of OSA. An investigation tool is not usually available in many hospitals [24]. Alternatively, good screening for OSA especially in obese patients using STOP-BANG questionnaire provides a high sensitive and negative predictive value tool to diagnose OSA in moderate to severe cases [12] [15].

Clinical observational studies had demonstrated a wide range of increased respiratory complication incidence in PACU, ranging from $1.3 \%$ to $34 \%$ taking in consideration the associated chronic medical illness and obesity related comorbidities [25] [26].

Kim JA et al. 2005 reported that OSA as an independent risk factor for perioperative respiratory events [27].

Scanty evidences are available describing the occurrence of respiratory complications of OSA patients at PACU] [28] [29].

It was reported that the majority of post-operative complications were found to be pulmonary in origin and mostly occurs after patients transfer from PACU to patients' word [30].

Mortality and morbidity can be aggravated by respiratory complications in post-operative period [31].

Our study showed that increased incidence of respiratory adverse events in 
high risk OSA patients compared with patients having low risk OSA.

Hypoxia was found to be more prevalent in OSA high risk group (group I) compared to low risk group (group II).

Those results were in accordance with Gali et al. who reported that more frequent respiratory complications were diagnosed among high risk of OSA patients [31]. A number of studies showed similar results [12] [27] [32].

Our results are also supported with what had been published by Chung et al. who stated that analysis of post-operative adverse events didn't show any significant respiratory complications in high risk OSA patients when compared to those with low risk group [32].

In our study, we reported respiratory muscle weakness as identified by inability to breathe deeply in almost one third of patients in both groups. This complication represented the most common adverse event with no significant difference between those having high risk of OSA and those haven't. This comes in agreement with recent studies in morbidly obese patients who did not find difference in respiratory events in either OSA or non-OSA patients [27].

Length of stay in PACU was found to be longer in group I (high OSA risk) which is in accordance with the majority of available studies [30] [31] [32].

Hospital stay and duration of anesthesia were both comparable in either groups and could be explained by the similarity of patient's characteristics and the procedure performed as bariatric surgery.

We performed the current study in only one center, Tanta University Hospital PACU which could participate in several study limitations.

Unavailability of PSG data for our patients represented a major limitation to accurately diagnose OSA and we consider only STOP-BANG questionnaire as a diagnostic tool for OSA rendering it difficult to categorize the severity of high risk OSA patients.

The inclusion of some subjective data when diagnosing respiratory events might affect the accuracy of diagnosis of respiratory complications, moreover we only considered respiratory compilations taking place in PACU where those occurring in patient's word were not included. This represented another added study limitation.

Still the small study sample size and single center could be considered as anther limitation to our study.

\section{Conclusions}

In conclusion, obese patients with STOP-BANG score of $>3$ undergoing bariatric surgery with high risk OSA are more frequently associated with hypertension, dyslipidemia, CAD, and renal insufficiency.

High risk OSA obese patients are at higher risk of developing respiratory compilations in the form of inability to breathe deeply and hypoxia in the post-operative PACU stay.

Patients with STOP-BANG $>3$ require a longer stay in PACU. 


\section{Conflicts of Interest}

The authors declare no conflicts of interest regarding the publication of this paper.

\section{References}

[1] Lettieri, C.J., Eliasson, A.H., Andrada, T., et al. (2005) Obstructive Sleep Apnea Syndrome: Are We Missing an At-Risk Population? Journal of Clinical Sleep Medicine, 1, 381-385.

[2] Young, T., Hutton, R., Finn, L., et al. (1996) The Gender Bias in Sleep Apnea Diagnosis. Are Women Missed Because They Have Different Symptoms? Archives of Internal Medicine, 156, 2445-2451.

[3] Yeh, P.S., Lee, Y.C., Lee, W.J., et al. (2010) Clinical Predictors of Obstructive Sleep Apnea in Asian Bariatric Patients. Obesity Surgery, 20, 30-35. https://doi.org/10.1007/s11695-009-9854-2

[4] Shafazand, S. (2009) Perioperative Management of Obstructive Sleep Apnea: Ready for Prime Time? Cleveland Clinic Journal of Medicine, 76, S98-S103.

[5] Sinha, A.C. and Singh, P.M. (2015) Controversies in Perioperative Anesthetic Management of the Morbidly Obese: I Am a Surgeon, Why Should I Care? Obesity Surgery, 25, 879-887. https://doi.org/10.1007/s11695-015-1635-5

[6] Marshall, N.S., Wong, K.K., Liu, P.Y., et al. (2008) Sleep Apnea as an Independent Risk Factor for All-Cause Mortality: The Busselton Health Study. Sleep, 31, 1079-1085.

[7] Young, T., Finn, L., Peppard, P.E., et al. (2008) Sleep Disordered Breathing and Mortality: Eighteen-Year Follow-Up of the Wisconsin Sleep Cohort. Sleep, 31, 1071-1078.

[8] Gallagher, S.F., Haines, K.L., Osterlund, L.G., et al. (2010) Post-Operative Hypoxemia: Common, Undetected, and Unsuspected after Bariatric Surgery. Journal of Surgical Research, 159, 622-626. https://doi.org/10.1016/j.jss.2009.09.003

[9] Memtsoudis, S., Liu, S.S., Ma, Y., et al. (2011) Perioperative Pulmonary Outcomes in Patients with Sleep Apnea after Noncardiac Surgery. Anesthesia \& Analgesia, 112, 113-121. https://doi.org/10.1213/ANE.0b013e3182009abf

[10] Young, T., Evans, L., Finn, L., et al. (1997) Estimation of the Clinically Diagnosed Proportion of Sleep Apnea Syndrome in Middle-Aged Men and Women. Sleep, 20, 705-706. https://doi.org/10.1093/sleep/20.9.705

[11] Ancoli-Israel, S., Kripke, D.F., Klauber, M.R., et al. (1991) Sleep-Disordered Breathing in Community-Dwelling Elderly. Sleep, 14, 486-495.

[12] Chung, F., Yegneswaran, B., Liao, P., et al. (2008) STOP Questionnaire: A Tool to Screen Patients for Obstructive Sleep Apnea. Anesthesiology, 108, 812-821.

[13] Finkel, K.J., Searleman, A.C., Tymkew, H., et al. (2009) Prevalence of Undiagnosed Obstructive Sleep Apnea among Adult Surgical Patients in an Academic Medical Center. Sleep Medicine, 10, 753-758. https://doi.org/10.1016/j.sleep.2008.08.007

[14] Chung, F., Yegneswaran, B., Liao, P., et al. (2008) Validation of the Berlin Questionnaire and American Society of Anesthesiologists Check-List as Screening Tools for Obstructive Sleep Apnea in Surgical Patients. Anesthesiology, 108, 822-830. https://doi.org/10.1097/ALN.0b013e31816d91b5

[15] Chung, S.A., Yuan, H. and Chung, F. (2008) A Systemic Review of Obstructive Sleep Apnea and Its Implications for Anesthesiologists. Anesthesia \& Analgesia, 
107, 1543-1563. https://doi.org/10.1213/ane.0b013e318187c83a

[16] Nagappa, M., Patra, J., et al. (2017) Association of STOP-Bang Questionnaire as a Screening Tool for Sleep Apnea and Postoperative Complications: A Systematic Review and Bayesian Meta-analysis of Prospective and Retrospective Cohort Studies. Anesthesia \& Analgesia, 125, 1301-1308. https://doi.org/10.1213/ANE.0000000000002344

[17] Romero-Corral, A., Caples, S.M., Lopez-Jimenez, F., et al. (2010) Interactions between Obesity and Obstructive Sleep Apnea: Implications for Treatment. Chest, 137, 711-719.

[18] Stierer, T.L., Wright, C., George, A., et al. (2010) Risk Assessment of Obstructive Sleep Apnea in a Population of Patients Undergoing Ambulatory Surgery. Journal of Clinical Sleep Medicine, 6, 467-472.

[19] Isono, S. (2009) Obstructive Sleep Apnea of Obese Adults: Pathophysiology and Perioperative Airway Management. Anesthesiology, 110, 908-921. https://doi.org/10.1097/ALN.0b013e31819c74be

[20] Patidar, A.B., Andrews, G.R. and Seth, S. (2011) Prevalence of Obstructive Sleep Apnea, Associated Risk Factors, and Quality of Life among Indian Congestive Heart Failure Patients: A Cross-Sectional Survey. The Journal of Cardiovascular Nursing, 26, 452-459. https://doi.org/10.1097/JCN.0b013e31820a048e

[21] Sin, D.D., Fitzgerald, F., Parker, J.D., et al. (1999) Risk Factors for Central and Obstructive Sleep Apnea in 450 Men and Women with Congestive Heart Failure. American Journal of Respiratory and Critical Care Medicine, 160, 1101-1106

[22] Hoffstein, V. and Szalai, J.P. (1993) Predictive Value of Clinical Features in Diagnosing Obstructive Sleep Apnea. Sleep, 16, 118-122.

[23] Liu, S.S., Chisholm, M.F., John, R.S., et al. (2010) Risk of Postoperative Hypoxemia in Ambulatory Orthopedic Surgery Patients with Diagnosis of Obstructive Sleep Apnea: A Retrospective Observational Study. Patient Safety in Surgery, 4, 9. https://doi.org/10.1186/1754-9493-4-9

[24] Pedersen, T., Viby-Mogensen, J. and Ringsted, C. (1992) Anaesthetic Practice and Postoperative Pulmonary Complications. Acta Anaesthesiologica Scandinavica, 36, 812-818. https://doi.org/10.1111/j.1399-6576.1992.tb03570.x

[25] Kim, J.A., Lee, J.J. and Jung, H.H. (2005) Predictive Factors of Immediate Postoperative Complications after Uvulopalatopharyngoplasty. The Laryngoscope, 115, 1837-1840. https://doi.org/10.1097/01.mlg.0000173199.57456.2b

[26] Hendolin, H., Kansanen, M., Koski, E., et al. (1994) Propofol Nitrous Oxide versus Thiopentone-Isoflurane-Nitrous Oxide Anesthesia for Uvulopalatopharyngoplasty in Patients with Sleep Apnea. Acta Anaesthesiologica Scandinavica, 38, 694-698. https://doi.org/10.1111/j.1399-6576.1994.tb03979.x

[27] Liao, P., Yegneswaran, B., Vairavanathan, S., et al. (2009) Postoperative Complications in Patients with Obstructive Sleep Apnea: A Retrospective Matched Cohort Study. Canadian Journal of Anesthesia, 56, 819-828.

[28] Gali, B., Whalen, F.X., Schroeder, D.R., et al. (2009) Identification of Patients at Risk for Postoperative Respiratory Complications Using a Preoperative Obstructive Sleep Apnea Screening Tool and Post Anesthesia Care Assessment. Anesthesiology, 110, 869-877. https://doi.org/10.1097/ALN.0b013e31819b5d70

[29] Fleiss, J.L., Williams, J.B. and Dubro, A.F. (1986) The Logistic Regression Analysis of Psychiatric Data. Journal of Psychiatric Research, 20, 195-209.

https://doi.org/10.1016/0022-3956(86)90003-8 
[30] Hwang, D., Shakir, N., Limann, B., et al. (2008) Association of Sleep-Disordered Breathing with Postoperative Complications. Chest, 133, 1128-1134. https://doi.org/10.1378/chest.07-1488

[31] Chung, F., Ward, B., Ho, J., Yuan, H., Kayumov, L. and Shapiro, C. (2007) Preoperative Identification of Sleep Apnea Risk in Elective Surgical Patients, Using the Berlin Questionnaire. Journal of Clinical Anesthesia, 19, 130-134. https://doi.org/10.1016/j.jclinane.2006.08.006

[32] Ahmad, S., Nagle, A., McCarthy, R.J., et al. (2008) Postoperative Hypoxemia in Morbidly Obese Patients with and without Obstructive Sleep Apnea Undergoing Laparoscopic Bariatric Surgery. Anesthesia \& Analgesia, 107, 138-143.

https://doi.org/10.1213/ane.0b013e318174df8b 